\title{
"A DIFICULDADE NÃO É FALAR, MAS LER FREUD EM PORTUGUÊS": UM OLHAR PARA AS PRÁTICAS DE LETRAMENTO NA EDUCAÇÃO SUPERIOR DE ESTUDANTES HAITIANOS NO BRASIL
}

\author{
"A DIFICULDADE NÃO É FALAR, MAS LER FREUD EM \\ PORTUGUÊS": A GLANCE AT LITERACY PRACTICES IN \\ HIGHER EDUCATION OF HAITIAN STUDENTS IN BRAZIL
}

Alan Silvio Ribeiro Carneiro*

\section{RESUMO}

Após o terremoto de 2010 que afetou a capital do Haiti, Porto Príncipe, o Brasil começou a receber progressivamente um número significativo de imigrantes do país caribenho. $\mathrm{O}$ foco da presente pesquisa é um grupo de estudantes haitianos que chegou ao Brasil, em 2011, por meio de um programa de cooperação que tinha, como um de seus objetivos, permitir àqueles que tiveram sua formação interrompida, em função do terremoto, a conclusão de seus estudos em universidades brasileiras. $\mathrm{O}$ autor do presente artigo esteve envolvido no acolhimento inicial desses estudantes em uma dessas instituições ensinando português como língua adicional e, mais tarde, em 2014, o autor propôs um curso específico para esse grupo, partindo do referencial teórico dos letramentos acadêmicos, considerando a proximidade da conclusão da graduação desses estudantes e a necessidade de elaboração de uma monografia final. O objetivo principal do presente artigo é apresentar o desenvolvimento desse curso específico, enfocando a regulação metapragmática dos posicionamentos dos participantes nas suas interações orais e escritas. A pesquisa foi conduzida partindo de um olhar etnográfico reflexivo com o registro das atividades em diário de campo, do registro em áudio das interações em sala de aula e das reuniões individuais e a organização de um arquivo das atividades escritas. A análise dos dados aponta para questões concernentes às relações de poder envolvidas na dinâmica de produção do conhecimento, aos processos de construção de um saber reflexivo sobre as práticas de leitura e escrita na universidade e ao desafio às convenções de escrita acadêmica. Ao final, reflito sobre as especificidades das práticas de letramento acadêmico em uma situação transnacional como a descrita, atentando brevemente para os potenciais impactos dessas práticas para os sujeitos que produzem esses textos e, mais amplamente, para a produção de conhecimento no/do Sul global.

Palavras-chave: letramentos acadêmicos; português como língua adicional; imigração haitiana (Brasil)

\footnotetext{
* Universidade Federal de São Paulo (UNIFESP), São Paulo, SP, Brasil. asilvio2002@yahoo.com.br 


\begin{abstract}
After the earthquake of 2010 that affected the capital of Haiti, Port-au-Prince, Brazil started progressively to receive an increasing inflow of immigrants from the Caribbean country. This research focus is on a group of Haitian students that arrived in Brazil, in 2011, through a cooperation agreement that had as one of its main aims to allow those affected by the earthquake to finish their undergraduate courses in Brazilian universities. The author of this paper was involved in the insertion of these students in one of the higher education institutions teaching them Portuguese as an additional language and, later on, in 2014, made a proposal of a specific course in this field for this group, based on the theoretical framework of academic literacies, taking into consideration that these students would be graduating soon and would have to write their thesis. The main aim of this article is to analyse the development of this specific course with a focus on the metapragmatics regulating the stances taken by the participants in their oral and written interactions. The research was conduced taking into consideration a reflexive ethnographic approach with the register of the development of activities in a research diary, as well with the audio register of the interactions in the classroom and in individual meetings and the organization of an archive of written tasks. The data analysis points out to issues related to the dynamics of power in the production of knowledge, the processes of building a reflexive knowledge about the literacy practices in higher education and the ways academic writing conventions would be challenged. In the final section, it is discussed the specificities of academic literacy practices in a transnational situation like this one, briefly looking at the potential impacts of these practices for the subjects writing these texts and, broadly, for the production of knowledge in the/from the Global South.
\end{abstract}

Keywords: academic literacies; portuguese as an additional language; haitian immigration (Brazil).

\title{
1. INTRODUÇÃO
}

Embora o contexto brasileiro seja marcado por uma ideologia hegemônica que vincula o Estado-nação à língua portuguesa, o que produz uma ausência de reconhecimento da diversidade linguística e cultural do país (PINTO, 2014), os usos dessa língua nos mais diversos cenários são marcados por múltiplas práticas heteroglóssicas (SIGNORINI, 2002, 2006, 2009, entre outros). Existem ainda várias zonas multilíngues, onde há uma diversidade de práticas translíngues e transculturais, ou em outras palavras, transglóssicas (ASSIS-PETERSON, COX, 2007), que são um fator de fricção em relação a essa hegemonia (COX; ASSIS-PETERSON, 2001; BORTONI-RICARDO; CAVALCANTI, 2007; CAVALCANTI, 2011; MOITALOPES, 2013; CAVALCANTI; MAHER, 2018; BIZON; DINIZ, 2018).

Esse complexo contexto linguístico e cultural é regulado por instrumentos ideológicos como as políticas linguísticas e educacionais, as quais demarcam formas legítimas e ilegítimas de usos linguísticos, (des)autorizando diferentes falas (SIGNORINI, 2006, 2008). Compreender essa configuração social, cultural e 
linguística implica entender os usos estratificados da língua portuguesa, mas também a emergência de novas práticas transglóssicas em antigas e novas zonas multilíngues do país, o que inclui os múltiplos cenários de imigração contemporâneos.

Dentre esses novos cenários devem ser incluídas as universidades brasileiras que, ao longo dos últimos anos, têm intensificado seus projetos de internacionalização. No contexto universitário, frequentemente, evidencia-se um processo de mobilidade comprometido com interesses que buscam promover uma internacionalização de mão de obra (KNIGHT, 2004; BOLSMANN; MILLER, 2008; STEIN, 2017). Interesses estes atravessados pelas dinâmicas de circulação do capital e da força de trabalho que também marcaram - e ainda marcam - os fluxos de mobilidade mais amplos no contexto brasileiro (PAIVA; MOURA, 2008; BAENINGER, 2013, entre outros) e em diferentes contextos do globo (SASSEN, 1990; MASSEY et al, 1999, entre outros).

Em meio a uma política de mobilidade que privilegia o diálogo das instituições de ensino superior brasileiras (IES) com instituições dos países centrais como ocorreu no direcionamento político do programa Ciência Sem Fronteiras (CsF), desenvolvido entre 2011 e 2017, há importantes programas de cooperação, com enfoque em países periféricos e semiperiféricos (WALLERSTEIN, 1974). Alguns deles já se encontram consolidados, como o Programa Estudantes Convênio de Graduação (PEC-G) e o Programa Estudantes Convênio de Pós-Graduação (PEC-PG), que têm uma história de mais de cinquenta anos. Outros são mais recentes, advindos de demandas sociais contemporâneas surgidas com as novas configurações geopolíticas e com a ocorrência de catástrofes naturais, como o Programa Emergencial Pró-Haiti, (BRASIL, 2010; THOMAZ; NASCIMENTO, 2010; CAPES, 2010; CARNEIRO; D'OLIVO, 2012; ALPHONSE; MACEDO, 2017; BIZON; DANGIÓ, 2018; SAINTIL, 2018), abordado neste artigo.

Assim sendo, nessa nova configuração do ensino superior brasileiro, são mesclados estudantes advindos de realidades socioculturais e linguísticas diversas. Nesse sentido, as IES brasileiras vêm buscando formalizar suas políticas de internacionalização e de línguas, reorganizando a demanda e a oferta de ensino das línguas adicionais, tendo em vista tanto brasileiros que saem em mobilidade para o exterior (ARCHANJO, 2016), quanto estrangeiros que chegam às IES brasileiras por meio de programas e convênios internacionais (BIZON, 2013; MIRANDA, 2016, BIZON; CAVALCANTI, 2018).

O enfoque desta investigação está em um grupo específico de imigrantes: estudantes haitianos trazidos ao Brasil pelo Programa Emergencial Pró-Haiti (doravante Pró-Haiti), por meio de um edital de cooperação internacional promovido 
pela Coordenação de Aperfeiçoamento de Pessoal de Nível Superior (BRASIL, 2010; CAPES, 2010). O projeto, estruturado pelos professores universitários Omar Ribeiro Thomaz e Sebastião Nascimento, tinha como objetivo permitir que um grupo de até 500 estudantes universitários haitianos pudesse vir ao Brasil para concluir seus cursos de graduação no período pós-terremoto (THOMAZ e NASCIMENTO, 2010).

O processo de seleção realizado pela Capes foi finalizado com 89 estudantes selecionados, no entanto, apenas 78 chegaram ao Brasil, ingressando em quatro universidades brasileiras, a saber: Universidade Estadual de Campinas (Unicamp), Universidade Federal de São Carlos (UFSCar), Universidade Federal de Santa Catarina (UFSC) e Universidade Federal do Rio Grande do Sul (UFRGS) (ALPHONSE; MACEDO, 2017; BIZON; DANGIÓ, 2018). Esses estudantes, ao chegarem no segundo semestre de 2011, tiveram acesso a um curso de língua portuguesa denominado Curso de Português Celpe-Bras, cujo objetivo era contribuir para a inserção desses jovens no meio acadêmico e em práticas sociais mais amplas ao longo do período de intercâmbio no Brasil. O programa, porém acabou por ser prolongado para que esses estudantes pudessem concluir seus cursos de graduação no país de mobilidade (CAPES, 2012a; 2012b).

$\mathrm{O}$ autor deste artigo esteve envolvido na primeira etapa de acolhimento desses estudantes haitianos, atuando como professor no curso de português como língua adicional ofertado pelo Centro de Ensino de Línguas (CEL), da Unicamp (CARNEIRO e D'OLIVO, 2012). Vale frisar que coube aos professores (supervisores e ministrantes) o planejamento do curso e a elaboração de materiais didáticos. Embora a orientação pedagógica para as atividades desenvolvidas partisse de uma perspectiva intercultural (MAHER, 2007a e 2007b), concebendo o espaço de aprendizagem em sala de aula como um lugar de trocas entre professores brasileiros e estudantes haitianos, ao longo do curso, havia momentos de convergência e de divergência cultural. Essas diferenças culturais devem ser entendidas aqui como diferenças metapragmáticas (SILVERSTEIN, 1993), ou seja, diferenças nas ideologias linguísticas que estruturam os enquadres e os alinhamentos nos posicionamentos (JAFFE, 2009) de professores e estudantes em relação às práticas construídas em sala de aula.

Carneiro e D'Olivo (2012), em um estudo sobre as ideologias linguísticas (WOOLARD; SCHIEFFELIN, 1994) de professores e estudantes no âmbito do curso Português Celpe-Bras, ofertado na Unicamp, exploraram essas diferenças metapragmáticas em relação ao entendimento dos participantes em torno das ideias de língua e ensino de línguas, em função das suas diferentes trajetórias sociais e 
dos processos de constituição de seus repertórios linguísticos e culturais. Os autores concluíram a discussão apontando a necessidade do desenvolvimento de uma consciência reflexiva dos estudantes não somente sobre os múltiplos usos da linguagem, mas também acerca das ideologias que estruturam esses usos, como forma de promover uma inserção mais significativa desses jovens em diferentes práticas sociais no Brasil.

Após a conclusão do curso de língua de 2011, na instituição em que o autor atuou, esses estudantes foram encaminhados para seus cursos de graduação na universidade, não havendo programa posterior previsto de acompanhamento em língua portuguesa. Como apontam Ferraz e Pinheiro (2014), em geral, ter condições de ser aprovado no exame Celpe-Bras não necessariamente implica apresentar um conjunto de conhecimentos linguísticos suficiente para o desenvolvimento das atividades acadêmicas. Para Lea e Street (1998, p. 158), "aprender na educação superior envolve uma adaptação para novos modos de conhecer: novas formas de entendimento, interpretação e organização do conhecimento"1.

Acompanhando, ainda que à distância, a trajetória desses estudantes haitianos no período posterior ao curso de português ofertado inicialmente, constatei, em conversas com alguns desses jovens, que a relação desses estudantes com as práticas de leitura e escrita acadêmica eram marcadas por sentimentos de exclusão. Sentimentos que, nesse contexto, acredito ser, pelo menos em parte, resultado daquilo que Lillis (1999) denominou como a "prática institucional do mistério", ou seja, um olhar ideológico que naturaliza as convenções das práticas de leitura e escrita acadêmica como se fossem senso comum, desconsiderando a trajetória dos estudantes não familiarizados com essas práticas e, consequentemente, dificultando a sua efetiva inserção na vida universitária.

Foi em um breve encontro coletivo com vários desses estudantes, realizado em 2013, que, em resposta à pergunta sobre como como estavam as práticas em língua portuguesa, uma das estudantes pronunciou os dizeres que intitulam este artigo: "A dificuldade não é falar, mas ler Freud em português". Ao meu ver, a fala indiciava que o foco de apreensão dos jovens, naquele momento, não era o conhecimento da língua em sua modalidade oral, mas as práticas de leitura, interpretação, escrita e apropriação das convenções de uso dessa língua no meio acadêmico.

Por essa razão e tendo em vista que o final da graduação de muitos desses estudantes estava próximo, o que demandava a escrita de uma monografia e/ou o interesse de alguns desses estudantes em ingressar na pós-graduação, que o autor

1. "Learning in higher education involves adapting to new ways of knowing: new ways of understanding, interpreting and organising knowledge." (Tradução do autor) 
deste artigo, em 2014, decidiu planejar e ofertar uma disciplina de leitura e escrita em português como língua adicional ${ }^{2}$. O objetivo principal do curso era contribuir para o aprimoramento da escrita de gêneros acadêmicos como o resumo, a resenha e o projeto de pesquisa, bem como aprofundar a compreensão dos estudantes sobre os contextos situados nos quais esses gêneros são produzidos. Isso implicava também refletir não apenas sobre as características de produção desses gêneros, mas também sobre o seu papel na vida acadêmica e no reconhecimento desses jovens como pesquisadores em potencial - algo bastante significativo em uma instituição de projeção internacional como era o caso da instituição em foco.

Paralelamente ao desejo de contribuir com a ampliação do repertório de práticas de leitura e escrita desses jovens, interessava-me refletir mais detidamente sobre o processo de inserção de estudantes pertencentes a programas de cooperação e mobilidade com países não centrais no contexto acadêmico brasileiro. Assim, foi desenhada uma pesquisa baseada no enquadramento dos letramentos acadêmicos (LILLIS; SCOTT, 2007) de modo a interrogar: a) as dificuldades desses estudantes com as práticas de leitura e escrita na instituição em foco; b) a sua dinâmica de aprendizagem sobre o funcionamento discursivo dessas práticas; e c) as possibilidades de desenvolvimento de materiais didáticos específicos para o ensino de português como língua adicional para fins acadêmicos ${ }^{3}$.

Cabe esclarecer que a compreensão de "letramentos acadêmicos" neste artigo o entende como uma prática social situada que envolve um horizonte de transformação (LILLIS; SCOTT, 2007). Segundo Lillis, Harrington, Lea e Mitchell $(2015$, p. 4):

\footnotetext{
"letramentos acadêmicos" são uma perspectiva crítica para o ensino e a pesquisa da escrita e do letramento, considerando o papel e o potencial dessas atividades para os processos individuais de construção de significado e a construção do conhecimento acadêmico nas instituições de ensino superior. ${ }^{4}$
}

O histórico de emergência desses estudos, na década de 1990, está vinculado ao ingresso de grupos minoritários/minoritarizados na universidade, em diferentes contextos nacionais (EUA, Reino Unido, África do Sul, entre outros), tendo em

2. O autor agradece ao CEL da Unicamp pela oportunidade de ofertar o curso gratuitamente em caráter de extensão.

3. Gostaria de agradecer Ana Cecília Cossi Bizon pelas discussões no momento de planejamento do curso e na preparação deste artigo. Os erros que permanecem, porém, são de minha inteira responsabilidade.

4. "Academic Literacies" is a critical approach to the researching and teaching of writing and literacy and to the role and potential of these activities for individual meaning making and academic knowledge construction in higher education." (Tradução do autor) 
vista processos de democratização do ensino superior (LILLIS; HARRINGTON, LEA; MITCHELL, 2015). No caso brasileiro, sua história é mais recente e encontra-se vinculada, principalmente, à área de língua materna do campo aplicado dos estudos da linguagem (FIAD, 2013 e 2015; PASQUOTTE; FIAD, 2015; FISCHER, 2015; FRANCO; CASTANHEIRA, 2016; SITO, 2018, entre outros). Porém, é importante notar o crescente interesse pelo letramento acadêmico em língua adicional, particularmente em língua inglesa, em virtude de projetos de internacionalização alinhados à visão de que é preciso produzir conhecimento em inglês. $\mathrm{Na}$ área de português como língua adicional, apesar da constatação do aumento na oferta de cursos para fins específicos nas IES brasileiras, ainda há poucas pesquisas voltadas ao estudo dos letramentos acadêmicos.

O objetivo principal deste artigo, portanto, é analisar o desenvolvimento do curso de língua portuguesa para fins acadêmicos que ofertei no ano de 2014, na universidade em foco, considerando a regulação metapragmática (SIGNORINI, 2008) das interações entre os participantes, incluindo o professor ministrante, no processo de ensino-aprendizagem. Para tal, inicialmente, apresento uma breve discussão sobre a imigração haitiana ao Brasil. Em seguida, descrevo o desenho do curso oferecido e o processo de geração de registros da pesquisa que ora focalizo. Em seção posterior, analiso os dados selecionados, os quais indiciam as dinâmicas situadas de construção de saberes sobre a as práticas de leitura e escrita acadêmica em questão, que envolvem relações de poder, os processos de construção de um conhecimento reflexivo e o desafio às convenções de escrita acadêmica. Ao final, reflito sobre especificidades das práticas de letramento em uma situação transnacional, atentando para os potenciais impactos dessas práticas para os sujeitos que produzem esses textos e, mais amplamente, para a produção de conhecimento no/do Sul Global.

\section{VISIBILIDADE E APAGAMENTO EM TORNO DA CONSTRUÇÃO DE IMAGENS DO HAITI E DO SER HAITIANO NO BRASIL}

Em 2010, o terremoto que atingiu o Haiti deu destaque ao pequeno país na arena global. $O$ evento, que deixou cerca de 300 mil mortos e 1,3 milhões de deslocados (HAITI, 2010, p. 7) ${ }^{5}$, sensibilizou a comunidade internacional, e muitos países, sobretudo centrais e semiperiféricos, disponibilizaram grandes

5. Conforme Alphonse e Macedo (2017) explicam em nota constante em seu artigo sobre o PróHaiti, não há consenso sobre esses dados entre as diversas instituições que fizeram esse tipo de levantamento, porém, eles são um indício das dimensões da tragédia que afetou o país. 
somas de recursos para a sua reconstrução - disponibilização que, não se pode esquecer, foi, em grande parte, motivada pela visibilidade que a ajuda humanitária internacional costuma projetar, assim como pelos interesses estratégicos no país e na região. Infelizmente, seguindo a lógica perversa desses mecanismos de apoio que se reproduz nos países mais pobres do globo, como era de se esperar, parte considerável desses recursos não chegou diretamente aos destinatários. Além disso, boa parcela do que chegou ao destino foi utilizada na própria manutenção dos funcionários envolvidos na promoção da ajuda internacional ao país ou ainda em projetos alinhados à agenda ou aos interesses dos doadores (Ver, por exemplo, SILVA, 2012; SILVA; SIMIÃO, 2012).

Nesse processo de visibilização promovido pela ajuda humanitária, as grandes proporções do terremoto contribuíram para colocar em evidência a atuação do Brasil no país, que, de 2004 a 2017, esteve no comando das tropas da Organização da Nações Unidas (ONU), sob a égide da Minustah (Mission des Nations Unies pour la stabilisation en Haïti) - a qual teria como objetivo garantir a paz no Haiti (PASSARELLI; TEIXEIRA, 2017). Lamentavelmente, em função do papel da ONU e dos interesses internacionais aos quais se vincula, a maior parte das ações da Minustah ficaram centradas em sua própria continuidade e no atendimento dos interesses das elites locais que se beneficiaram do contingente militar presente no país, o qual na visão de diversos pesquisadores teve como função principal o controle da população civil e a repressão dos movimentos sociais (SEGUY, 2014 e 2015; REIZ; O’LEAR, 2016).

Esse jogo de visibilidade e apagamento, no qual ficou em evidência quem estava doando mais ao Haiti, bem como o professado papel humanitário da missão brasileira no país, contribuiu para a invisibilização de uma dada lógica, não exatamente humanitária, muitas vezes presente na prática de ajuda internacional. Jogo bastante similar ao reproduzido nas imagens divulgadas internacionalmente após o terremoto que, supervalorizando escombros, cadáveres, pobreza, desespero e desolação, acabavam por apagar as redes de solidariedade e apoio entre os próprios haitianos, os quais têm procurado resistir às diversas formas de poder e dominação impostas ao país e a sua população (THOMAZ, 2010 e 2011). Nos principais mecanismos de busca de imagens na internet, digitando palavras como "terremoto Haiti", "earthquake Haiti" ou "tremblement Haiti", pouco se encontra do que o antropólogo Omar Ribeiro Thomaz (2010, p. 27) descreve a partir da sua presença no território caribenho durante o terremoto: 
Todos estavam nervosos, mas ninguém ameaçava ninguém, todos se ajudavam. Descemos rumo ao centro, e a todos cumprimentávamos e éramos correspondidos: Bonjou madanm; Bonjou mesye; Bonjou frè mwen; Sali!.

O Champs-de-Mars fora transformado num imenso campo de refugiados. Mas transformado pela população que se organizara, improvisara tendas e barracas. Grupos de homens se organizavam em brigadas, escoteiros impecáveis transitavam ajudando os feridos, jovens vestidos com camisetas da mesma cor trabalhavam nos escombros e coletavam lixo. Caminhões pipa distribuíam água gratuita para uma população organizada em filas. Tratava-se de uma iniciativa de empresários haitianos. Não bá nenbuma presença nem da ONU, nem de nenbuma organização internacional. Os brancos desapareceram da cidade. Somos os únicos brancos, para além de alguns carros que passavam a toda velocidade com alguns jornalistas e fotógrafos. Estes profissionais desciam diante do Palácio Nacional, tiravam algumas fotos, e voltavam a subir; paravam diante das pilhas de mortos, e das janelas dos carros faziam suas fotos.

No Google/Brasil, digitando apenas "Haiti" na busca por imagens, encontram-se resultados desse mesmo apagamento: surgem imagens de favelas e pessoas em meio ao esgoto e ao lixo, misturadas com mapas e imagens do terremoto. Nesse sentido, pode-se dizer que a tônica da pobreza domina a construção de um imaginário sobre o Haiti, reproduzido como senso comum inescapável não apenas em imagens, mas também no discurso, por meio da descrição mais recorrente da grande mídia brasileira, que o predica como o "país mais pobre das Américas" ou, ainda mais dramaticamente, "do Hemisfério Ocidental". Assim, a exaltação da pobreza produz o apagamento das riquezas naturais do território haitiano, de sua herança histórica, cultural e religiosa, da diversidade de suas paisagens geográficas, entre outros aspectos que compõem a nação haitiana. Os mecanismos de busca online, enfim, reproduzem a construção do Haiti unicamente como um país pobre, restringindo as possibilidades de construção de outros imaginários acerca de suas características e construções culturais.

Ademais, se a palavra digitada no Google Brasil for "haitianos", o que aparece é um conjunto de imagens que, também partindo desse imaginário da pobreza, revelam haitianos em diferentes situações de vulnerabilidade: em alojamentos precários, esperando por comida e remédios, em filas ou sentados, sem que se saiba exatamente o que esperam ou o que estão fazendo. Também aparecem imagens de haitianos com a carteira de trabalho brasileira. Nesse caso, então, mais do que a projeção de um haitiano genérico, tal qual surge quando se busca pelas palavras "terremoto" e "Haiti", os resultados para "haitianos" projetam uma representação desses indivíduos como "imigrantes". Assim, com este trabalho, na mesma direção de outras pesquisas recentes (BERSANI e JOSEPH, 2017), pretendo contribuir para a possível desconstrução dessas imagens, buscando visibilizar as vivências 
desses imigrantes para além do que esses lugares discursivos verbais e imagéticos têm fixado.

Pode-se dizer que os estudantes haitianos do Pró-Haiti foram o primeiro grupo considerável de haitianos a chegar no Brasil, em 2011, no período pósterremoto. Em sala de aula como professor, acompanhei, com os estudantes da minha turma - em meio a choro e tristeza -, a chegada em condições precárias dos primeiros imigrantes do Haiti, na fronteira do Acre. Naquele momento, a formação de uma rede de migração, considerando-se origem, etapa e destino, configurouse como um desafio político, econômico e diplomático para o Estado brasileiro, culminando na política de concessão de visto humanitário. Segundo Baeninger e Peres (2017, p. 128), para quem a migração haitiana modificou a cartografia das migrações no Brasil, entre 2010 e 2015, entraram no Brasil aproximadamente 85.000 haitianos. Desses, cerca de 28.000 entraram com visto permanente, com uma parcela significativa conseguindo se inserir no mercado formal de trabalho. Parte considerável desse contingente, porém, conforme pontuam as autoras, encontravase - e ainda se encontra - em condições precárias de trabalho.

Em relação aos números e às trajetórias dos estudantes do Pró-Haiti, em uma das universidades do programa, por exemplo, Alphonse e Macedo (2017) indicam que, dos 41 que chegaram à Unicamp, 36 permaneceram na universidade. Em 2013, 29 estavam regularmente matriculados na graduação e 7 em cursos de pós-graduação. A pesquisa de Alphonse e Macedo, com dados de 2016, mostra que um número significativo de estudantes concluiu seus cursos, ingressando na pós-graduação. Até o fechamento deste artigo, parte desses estudantes encontrava-se com seus cursos em andamento, o que aponta para um processo efetivo de construção de estratégias de inserção desses estudantes no contexto universitário.

Apesar disso, Bizon e Dangió (2018), em um estudo qualitativo que considera as narrativas de estudantes do Pró-Haiti em uma das universidades receptoras, identificaram processos de racialização vividos pelos jovens, bem como certo apagamento de suas identidades e trajetórias no espaço universitário. Em um caso bastante emblemático, uma estudante relata episódios de rejeição, chegando a ser tratada por colegas e até professores como alguém que não deveria estar naquele espaço. Relata também experiências em que se notam preconceito e xenofobia por parte dos brasileiros, alicerçados em estereótipos dos haitianos como uma população miserável e pelo Haiti como um território reconhecido apenas por catástrofes naturais, desestruturação política e pobreza. Bizon e Dangió chamam a atenção também para projetos de internacionalização das universidades que nem 
sempre consideram as especificidades de estudantes de países periféricos e sua potencial contribuição no ambiente universitário.

Saintil (2018) faz um relato pessoal de seu processo de inserção em uma das universidades e relata a sua aprendizagem da língua portuguesa. Em sua narrativa, o jovem explica como essa língua mediou sua relação com a realidade brasileira e com a universidade. Saintil reconhece algumas ações do curso de 2011 - por exemplo, as saídas programadas a um jogo de futebol em um estádio da cidade, ao teatro, a visita a museus - como parte essencial do processo de acolhimento. Contudo, também aponta falhas nesse processo, destacando dificuldades enfrentadas pelos estudantes do programa no ambiente universitário e fora dele. $\mathrm{O}$ autor fala, por exemplo, de modificações que seriam necessárias no curso de português, que deveria ter levado para a sala de aula uma língua mais "real", do dia a dia, com registros mais informais da língua portuguesa, e menciona o papel do aprendizado do português acadêmico a sua inserção e na de outros estudantes na vida universitária.

O relato de Saintil, atravessado por suas experiências de aprendizado da língua portuguesa, marcado também pelo aprendizado cultural, traz, em alguma medida, uma dimensão importante do processo de inserção dos estudantes haitianos no contexto brasileiro. Mais do que isso, revela o papel dessa língua nesse processo quando afirma "a aprendizagem do português foi e continua sendo uma experiência enriquecedora e única, com a qual venho ampliando as possibilidades de enxergar o mundo, construindo meu presente e pensando meu futuro" (SAINTIL, 2018, p. 167).

O curso implementado em 2014 pelo autor do presente artigo e que será relatado no próximo item aponta para a forma como esse processo de inserção dáse no cotidiano da sala de aula, explicitando os diferentes modos de apropriação da língua portuguesa como um lugar de enunciação para esses sujeitos, mas também para os processo de manutenção das línguas e de aspectos da cultura haitiana no contexto diaspórico. Se as imagens construídas pela mídia e pelo senso comum em torno dos haitianos e da imigração haitiana são homogeneizantes, as suas vivências indiciam estratégias heterogêneas e criativas de construção de suas vozes sociais.

\section{UMA INTERVENÇÃO NO CAMPO DOS LETRAMENTOS ACADÊMICOS COM ESTUDANTES HAITIANOS EM UMA UNIVERSIDADE PÚBLICA BRASILEIRA}

Como apontado anteriormente, desde o final dos anos de 1990 (LEA e STREET, 1998), as práticas de leitura e escrita no âmbito acadêmico começaram a ser analisadas sob a ótica dos estudos do letramento. Mais do que uma mudança 
de título, tratou-se de uma mudança conceitual, que passou a considerar a escrita como uma prática social ideologicamente marcada e demandante de uma pedagogia específica (LILLIS, 2003; LILLIS; SCOTT, 2007; CARTER; LILLIS; PARKIN, 2009, entre outros). O curso de leitura e escrita em português como língua adicional oferecido no segundo semestre de 2014 como um curso de extensão na Unicamp, teve como um dos seus objetivos contribuir para o desenvolvimento dessa pedagogia na instituição, tendo em vista as demandas dos estudantes estrangeiros, especialmente aqueles provenientes do Sul global.

Foram recebidas dezoito inscrições para o curso, sendo dezesseis de participantes do Programa Pró-Haiti e duas do PEC-G (uma estudante proveniente da Guiné-Bissau e um de Timor-Leste) ${ }^{6}$. Houve três desistências de haitianos. Grande parte dos alunos estava em cursos de Humanas (Letras, Linguística, Economia, Geografia, Ciências Sociais, História e Pedagogia) e um pequeno número em cursos de Exatas (Física e Estatística).

Do ponto de vista metodológico, a ideia era de que o curso, prevendo o diálogo entre formador e estudantes e tendo em vista a experiência relatada por Carneiro e D’Olivo, pudesse promover o desenvolvimento de uma consciência crítica sobre o funcionamento dos gêneros (DEVITT, 2009). Para tal, seriam realizadas atividades de análise e de produção de textos acadêmicos diversos, como resumos, resenhas, artigos, ensaios e projetos de pesquisa, de modo a evidenciar o seu papel nas práticas de produção de conhecimento.

O curso de 60 horas foi estruturado em três módulos e oferecido de setembro a novembro de 2014, contando com aulas com todo o grupo e com atendimentos individuais. Cada módulo enfocava um gênero específico, tendo como inspiração os trabalhos de Machado, Lousada e Abreu-Tardelli (2004a, 2004b e 2005): Módulo I - O gênero resumo escolar e acadêmico; Módulo II - O gênero resenha acadêmica e Módulo III - Introdução ao projeto de pesquisa.

A princípio, todos os módulos seriam desenvolvidos seguindo os mesmos passos: (i) discussão do funcionamento discursivo do gênero focalizado; (ii) sistematização desse funcionamento a fim de subsidiar a produção escrita do gênero estudado; (iii) produção de texto e (iv) análise coletiva de alguns textos produzidos. Contudo, em função da carga didática limitada, o cumprimento de todas as etapas foi realizado apenas no primeiro módulo, que durou aproximadamente seis semanas.

6. Embora o curso tenha sido aberto para estudantes do PEC-G e PEC-PG, apenas esses dois estudantes manifestaram interesse. Vale destacar também que, mesmo o curso sendo aberto para quaisquer estudantes do Pró-Haiti, apenas aqueles que mantinham certa proximidade com o autor se matricularam. 
Nos módulos seguintes, foi trabalhada a discussão e a sistematização dos gêneros em foco, mas não foi possível trabalhar de forma sistemática a produção escrita, pois o segundo e o terceiro módulo tiveram, cada um, apenas três semanas. Porém, como havia em paralelo os atendimentos individuais, pude conversar nesses encontros sobre as dificuldades que os estudantes tinham na leitura e na escrita de trabalhos em seus cursos de graduação, fosse, por exemplo, na redação de trabalhos finais, resenhas e ensaios produzidos para disciplinas, fosse na elaboração de projetos de monografia e de mestrado. Dessa forma, o curso percorreu um caminho ao longo das aulas focado nos módulos propostos, o qual era seguido por todos estudantes, mas, ao mesmo tempo, cada aluno percorreu um caminho específico a partir dos seus interesses e demandas nos atendimentos individuais.

O fundamento (meta)metodológico e (meta)teórico da investigação desenvolvida baseou-se na perspectiva da linguística aplicada brasileira, que se constitui em diálogo com as teorias sociais e as teorias críticas produzidas internacionalmente (MOITA-LOPES, 2006 e CAVALCANTI, 2006). Nessa direção, a pesquisa foi inspirada em um horizonte etnográfico que considera as práticas de letramento em seus contextos situados de produção e parte de uma negociação cuidadosa feita com os participantes desde antes do início do curso.

Para a negociação relativa ao registro dos dados necessários para a investigação, primeiramente, foi apresentada aos estudantes a necessidade institucional de ter mais informações sobre as suas dificuldades com a língua portuguesa para melhorar o acolhimento aos estrangeiros. A oferta do curso tinha como um dos seu horizontes a produção de um relatório a ser entregue para o centro de línguas, com o objetivo de subsidiar o planejamento das atividades da área de língua portuguesa para a organização de futuros cursos.

No diálogo com os estudantes, foi explicitada essa necessidade como uma justificativa para que eles pudessem colaborar com a proposta. Apesar disso, a participação no curso era livre e o consentimento foi negociado de forma individual com cada um deles, pois ainda não existiam normativas padronizadas para avaliação da proposta em um Comitê de Ética em Pesquisa institucional. Apenas após essa negociação é que se iniciou o registro das atividades em áudio e o registro das atividades escritas dos estudantes. Até então, a principal ferramenta de registro foram os relatos produzidos no diário de campo. Nesse sentido, as 10 horas de gravações em áudio das interações em sala de aula e das orientações individuais, bem como o registro das atividades escritas, são complementares a esses relatos

Os dados foram tematizados e codificados a partir de três eixos analíticos entrelaçados: o papel das relações de poder na produção de conhecimento que 
emergiam, por exemplo, nas diferentes reflexões sobre aspectos institucionais desse processo e que estavam presentes frequentemente nas reuniões de orientação individual (marcados como RP); os aspectos específicos da aprendizagem da dinâmica de produção do conhecimento que eram manifestados, por exemplo, nas reflexões individuais e coletivas em sala de aula (marcados como PC) e, de forma conexa, a aprendizagem das convenções dessa escrita, sobretudo no que se refere ao uso de recursos linguísticos específicos, presentes nas atividades que foram entregues pelos estudantes (marcados como CEA). Cabe destacar que, ao longo das análises, os registros poderiam ser codificados com mais de uma notação, de modo que a escolha eventual de uma delas estava relacionada aos aspectos mais salientes na interação em termos discursivos (WORTHAM, 2001, p. 37). No próximo item, pretendo analisar os posicionamentos que apontam para essas dinâmicas e a forma como eles emergiram no contexto da sala da aula.

\section{APRENDENDO A POSICIONAR-SE: CONSTRUINDO SABERES E DESAFIANDO AS CONVENÇÕES DE ESCRITA ACADÊMICA}

A análise empreendida neste artigo quer responder de forma mais específica à pergunta de pesquisa inicial sobre o funcionamento da dinâmica de aprendizagem ao longo do curso. Para tal, foi analisado o funcionamento das marcações codificadas nos dados relacionadas a PC (aprendizagem da dinâmica de produção do conhecimento) e a CEA (aprendizagem das convenções de escrita acadêmica), buscando as pistas de contextualização - os índices que ocorrem no discurso e que orientam os interlocutores sobre o que está acontecendo no contexto - e o funcionamento das metapragmáticas e das ideologias linguísticas que, de forma situada, regulam os posicionamentos dos sujeitos.

A análise dos dados ficou concentrada, então, na consideração sobre os modos de construção dos diferentes posicionamentos dos participantes nas interações $(J A F F E, 2009)^{7}$ que ocorreram nas reuniões de atendimento individual,

7. Na tese de doutorado de Carneiro (2014), há um detalhamento sobre a discussão do conceito de "stance", como debatido por Jaffe (2009) no campo da sociolinguística. Na tese, o termo está traduzido como "estância", partindo da discussão no campo dos estudos da linguagem de Du Bois (2007), para diferenciá-lo do termo "posicionamento", tradução que caberia melhor ao termo "positioning", tal como ele aparece na tradição dos estudos de psicologia social (HARRÉ e VAN LANGENHOVE, 1991 e HARRÉ e VAN LANGENHOVE, 1999). Neste artigo, a opção do autor foi pelo uso do termo posicionamento em uma dimensão ampla, evitando o neologismo, tendo em vista que a discussão proposta por Jaffe (2009) não se contrapõe, mas incorpora os debates de múltiplos campos do conhecimento sobre a tomada de posições na interação, incluindo as discussões da psicologia social. 
nas aulas e nas atividades escritas, observando os recursos linguísticos salientes que sinalizavam as características das posições em questão. Como afirma Jaffe (2009, p. 4):

(...) speakers and writers are necessarily engaged in positioning themselves vis-à-vis their words and texts (which are embedded in histories of linguistic and textual production), their interlocutors and audiences (both actual and virtual/projected/imagined), and with respect to a context that they simultaneously respond to and construct linguistically (JAFFE, 2009, p. 4).

Os posicionamentos tomados pelos estudantes e pelo professor ministrante - no que se refere à compreensão do processo de produção de conhecimento e àqueles que revelam sua forma de relação com as convenções de escrita acadêmica - indiciam seus percursos de formação, suas filiações teóricas e epistemológicas diversas. Esses posicionamentos são carregados ou loaded (COUPLAND, 2007, p. 114) pela forma como suas identidades foram constituídas ao longo do tempo em diferentes espacialidades e temporalidades.

Pretendo apresentar dois conjuntos de dados que demonstram esse funcionamento. No caso do primeiro, em que são apresentadas discussões realizadas nas aulas a partir da leitura de resenhas e de projetos de pesquisa, as pista de contextualização que indiciam o funcionamento discursivo em curso são duas metáforas, uma primeira, que indica o modo de compreender o tom - nos termos de Hymes (1972), keying - do gênero resenha, e uma segunda, que indica um modo específico de compreender a repetição de conteńdo, aspecto estilístico presente no gênero projeto de pesquisa. No segundo conjunto de dados, em que é apresentada uma discussão a partir da escrita de um projeto de pesquisa de um estudante, a pista de contextualização é o posicionamento do "eu" no texto, que emerge como uma questão em uma relação de tensão com as convenções da escrita acadêmica.

\section{Leituras: construindo saberes sobre o fazer acadêmico}

Como afirmado anteriormente, o aspecto pedagógico central do curso era o desenvolvimento da consciência de gênero, não como um mero exercício de distanciamento, mas como uma forma de apropriação ativa desses recursos linguísticos (DEVITT, 2009). As aulas ocorriam duas vezes por semana e tinham em torno de uma hora e meia; em cada uma das aulas, havia vídeos, textos, discussão e sistematização das características dos gêneros, bem como a redação de exercícios breves e mais longos, esses últimos em casa, com a discussão posterior dos resultados. No começo, a regulação da interação era marcada por uma hierarquia clara entre professor ministrante e estudantes e por uma complexa negociação de horizontes 
de expectativas em torno de como conceber a linguagem, a escrita acadêmica, a autoria e a produção de conhecimento, o que revelava que as diferenças culturais observadas por Carneiro e D’Olivo (2012) ainda estavam presentes.

$\mathrm{Na}$ sala de aula, era comum o uso constante do crioulo haitiano nas atividades em grupo, o que representava um contraponto radical em relação à recusa que os estudantes apresentaram, em 2011, em utilizar esse recurso linguístico no curso inicial de português como língua adicional, ainda que isso fosse algo estimulado pelos professores. Em 2014, o crioulo haitiano era utilizado para debater ideias e construir conhecimento no âmbito dos grupos, a ser socializado posteriormente em língua portuguesa, como aparece no relato do diário de campo, reproduzido abaixo:

$1 \mathrm{Na}$ aula de hoje, continuamos a atividade anterior de sistematização do funcionamento das resenhas. Quando cheguei os alunos haitianos estavam discutindo em crioulo, como percebi que a discussão estava intensa, perguntei sobre o que eles estavam falando, eles disseram que era sobre o perfil e o legado do ex-presidente haitiano Jean Bertrand Aristide. Retomei os exercícios e pedi para eles responderem, eles demoraram um pouco mais do que eu esperava, mas conseguiram fazer com facilidade. 2 Em um dado momento enquanto sistematizava a estrutura, mencionei um pouco sobre a polidez necessária e conveniente na escrita das resenhas, falei da estrutura, do cuidado necessário com as críticas, eles entraram em uma conversa bem intensa em crioulo sobre o que eu havia dito. 3 Perguntei sobre o que eles estavam falando, eles me disseram que não podiam expressar o que era, que era algo específico do crioulo, insisti mais um pouco e eles vieram com a expressão em haitiano que quer dizer algo como "morde e assopra". Essa foi a síntese do gênero nessa aula. ${ }^{8}$

O excerto do diário relata o funcionamento do cotidiano da sala de aula. O meu posicionamento é marcado por uma enquadre que apresenta uma visão técnica da linguagem da resenha como aparece no relato, no segmento 2, que busca desvelar a "prática institucional do mistério". Em 3, de forma colaborativa, a síntese apresentada após a discussão em crioulo haitiano sobre a escrita da resenha é traduzida com a expressão "morde e assopra", que emerge como uma metáfora para o procedimento, característico do gênero resenha, de criticar de forma polida.

$\mathrm{Na}$ discussão em torno dessa metáfora, um aspecto da cultura haitiana é rememorado pelo procedimento estilístico presente no gênero de criticar polidamente. Embora na discussão inicial relatada, a princípio, o grupo pensasse que não havia um termo equivalente na cultura brasileira, por meio de um esforço coletivo, é buscada uma expressão cultural que represente essa ideia. Nessa interação, múltiplas ordens de indexicalidade, ou seja, as múltiplas ordens normativas que regulam a semiose (BLOMMAERT, 2005, 2007), são colocadas em jogo, remetendo às trajetórias de aprendizagem de professor ministrante e estudantes. A expressão

8. O negrito serve para marcar os elementos que foram salientes na primeira análise. 
de caráter popular utilizada no Haiti é colocada em paralelo com uma expressão similar em português, que, por sua vez, representaria o tom, keying (HYMES, 1972) necessário para dominar o gênero resenha. $\mathrm{O}$ exercício da tradução dessa forma, não é apenas um exercício de tradução linguística e cultural, mas também de tradução de lugares de saberes distintos que são aproximados nesse evento.

Essa forma de produzir conhecimento, buscando aliar espaços culturais distintos, caracterizada nesse uso de uma expressão metafórica, foi utilizada também em outros eventos, como, por exemplo, na apresentação de um seminário de análise de projetos de pesquisa realizados pelos estudantes. Aqueles que apresentariam um projeto da área de ciências sociais planejaram a discussão com uma introdução sobre a importância do tema na redação do projeto de pesquisa o que remetia às aulas anteriores sobre o gênero. Segue o trecho da transcrição:

E1: Então... antes de começar a apresentação \{trecho incompreensível\} sobre o projeto eu queria colocar uma música para vocês ouvirem ...

(excerto suprimido)

E2: Será mais interessante se vocês prestarem atenção para ver como... a estrutura da música... abaixa... abaixa

\{E1 coloca um videoclipe por três minutos tocando a Sinfonia № 5 de Beethoven $\}$

E1: ok, o que eu queria dizer com essa música com relação ao nosso projeto é a questão da... do que... da pesquisa... a música $\{\mathrm{E} 2$ ajeita cadeiras na frente da sala $\} ..$ a música, a introdução da música, o tema da música, quando ele vai sair da introdução, no desenvolvimento da música ele retoma o tema da música, isso explica como o tema da pesquisa é sempre presente desde o começo da pesquisa, em todo o processo da pesquisa, sempre eu vou estar retomando o tema da pesquisa.

A linguagem musical emerge aqui como uma metáfora para um outro aspecto estilístico do texto acadêmico relevante para o projeto de pesquisa, a repetição do tema de diferentes formas no sentido de caracterizá-lo e justificar a sua importância. A música utilizada aqui já não remete a algo típico haitiano, mas a algo que é entendido como universal. Nesse sentido, aqui há uma pista de contextualização distinta daquela construída com as sucessivas recontextualizações realizadas em crioulo haitiano e em português para chegarmos ao termo "morde e assopra". No caso desse exemplo, a música e a ciência são justapostas lado a lado por suas características estruturais. O recurso linguístico é o mesmo do dado anterior, a 
metáfora, e do ponto de vista cognitivo, produz o mesmo efeito: a compreensão de um elemento estilístico da linguagem acadêmica na medida em que funciona como uma metonímia para lembrar um aspecto relevante desse gênero. Porém, os modos de significação, em cada uma das metáforas são distintos e revelam a circulação desses estudantes por diferentes universos culturais como o da cultura popular haitiana, no caso da expressão idiomática do crioulo e o da cultura erudita, no caso da música clássica.

\section{Escritas: desafiando as convenções acadêmicas}

A escrita acadêmica é regulada por um sistema que se consolidou ao longo do tempo, mas esse sistema também se transforma, de modo que determinadas regulações, comuns há não muito tempo atrás, deixam de sê-lo. Por exemplo, até o século XIX, uma das principais línguas da ciência ainda era o latim, o que permaneceu até muito recentemente como um resquício em expressões latinas para a escrita científica como "idem", "ibidem", "op. cit.", as quais, recentemente, começaram a cair em desuso.

A construção da figura de um "eu" acadêmico é um elemento fundamental dessa escrita. Saber modalizá-lo pode indiciar o grau de certeza nas afirmações acadêmicas, sentimentos em relação aos objetos de estudos, as relações com os diferentes outros implicados no texto, a construção de uma identidade como autor e a ocupação de um lugar como produtor de conhecimento, entre outros aspectos. No entanto, em vários materiais didáticos que têm uma perspectiva mais normativa sobre a escrita acadêmica, a orientação é de que é melhor não usar muito uma linguagem pessoal, o que inclui, por exemplo, evitar o uso da primeira pessoa "eu", e, na atualidade, rejeitar, o uso do "nós", conhecido como plural majestático ou de modéstia.

Os textos repassados pelos estudantes e que foram registrados como parte do arquivo da pesquisa apontavam características diversas, desde textos baseados em cópias de trechos ou paráfrases muito próximas dos textos originais, até aqueles que reproduziam ainda opiniões no modelo dissertativo de escrita escolar. Porém, havia textos que já se caracterizavam por apresentar padrões estilísticos próximos de modelos canônicos dessa escrita, o que aponta para a diversidade de trajetórias de formação dos estudantes do curso.

É importante considerar, no entanto, que, apesar desses textos estarem mais próximos dessa estilística padronizada, eles apresentavam também construções específicas de pessoalidade, mostrando modos singulares de posicionar o sujeito autor. Esses elementos, por sua singularidade, eram eventualmente comentados nas 
correções de texto, como no exemplo abaixo, discutido também em um excerto do diário de campo:

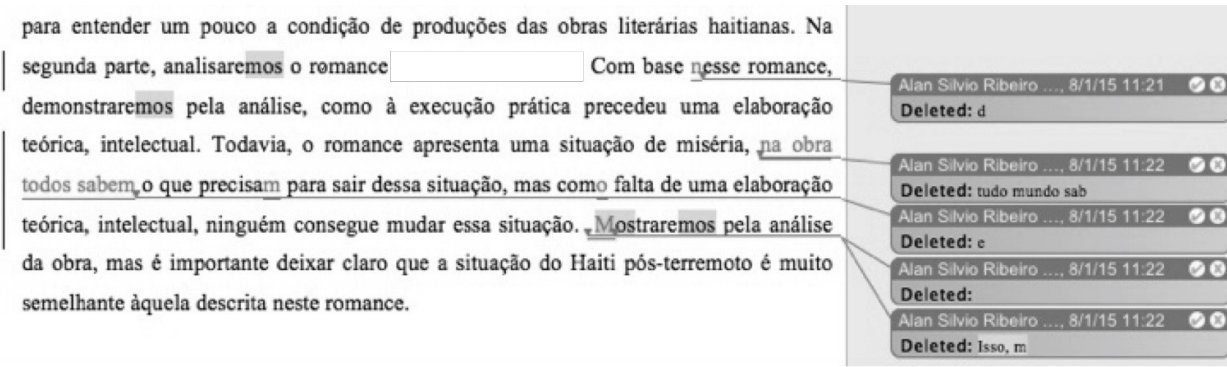

Figura 1. Excerto de trabalho.

1 Pela manhã encontrei com E3, ele havia feito um trabalho muito bom sob a orientação do Professor N, elogiei o trabalho dele e falei que certamente ele poderia pedir uma bolsa da FAPESP com esse projeto. 2 Ele falou que o $\mathrm{N}$ não dá orientações muito específicas e que o processo foi marcado por muitas tentativas de escrita e reescrita, ele falou que para o $\mathrm{N}$, o aluno vai trabalhar com aquilo que tem, ele deve trabalhar sozinho com o seu conhecimento e a sua ignorância. 3 Ele contou que teve a ajuda de um colega para revisão, mas pelo estilo de escrita era possível verificar que ele já tinha um domínio sofisticado das práticas de escrita acadêmica, apesar de pequenas marcas que emergiam no seu texto que atualizavam suas práticas de escrita em francês no Haiti. 5 Isso aparecia em determinadas escolhas lexicais e, por exemplo, na sua insistência em utilizar o plural de modéstia, mesmo, tendo recebido indicações para que não fizesse isso. 6 Ele mencionou haver várias correções que ele não aceitou na sua escrita do texto.

Com o mesmo enquadre do professor que corrige esses elementos buscando uma perspectiva mais técnica - nem por isso, menos ideológica -, ao longo do texto, foram marcados os lugares onde o plural de modéstia aparece, como pode ser visto na Figura 1. Na reunião de orientação individual, conforme registro no diário de campo, o clima era amigável e o tom do professor ministrante em relação ao texto era elogioso, como aparece em 1. Em 2, é relatada a conversa de ambos sobre a relação do estudante com seu orientador que indicia parte da história de produção do texto do seu projeto de pesquisa. No caso em questão, o pressuposto do orientador é de que o estudante já deveria ter o domínio da leitura e da escrita acadêmica, bem como dos instrumentos de pesquisa necessários para o seu desenvolvimento como pesquisador.

Em 3, são trazidos mais elementos sobre a história do texto, os quais são justapostos à reflexão do professor ministrante sobre a sua forma de interpretar as 
formas pela qual o estudante constrói uma forma específica de pessoalidade ali. Para o professor, esses elementos remetem a sua trajetória pregressa com as práticas de leitura e escrita no Haiti, com uma pressuposição de que, no contexto brasileiro, essas formas não seriam adequadas. Em 4, está implícito que isso foi um tema de discussão e que gerou uma conversa mais longa na reunião, o que levou o professor ministrante a interpretar que o estudante não estava interessado em incorporar todas as correções como uma forma de afirmação identitária: "Ele mencionou haver várias correções que ele não aceitou na sua escrita do texto."

A interpretação inicial registrada no diário do professor ministrante é de que esse uso do plural de modéstia era uma marca estilística trazida do Haiti e uma opção pessoal para firmar um discurso individual na academia que fosse representativo da trajetória do estudante. Porém, reavaliando essa interpretação inicial que produzi naquele momento, penso que, embora o fator identitário esteja presente como uma ordem indexical, creio que esse plural de modéstia indicie também uma outra ordem de indexicalidade. Considerando que a transnacionalidade produz um tipo específico de consciência (VERTOVEC, 1999) marcada por memórias e por projeções entre os múltiplos lugares de vivência e de passagem dos sujeitos migrantes, passei a compreender que o "nós" de E3 poderia representar um "nós" inclusivo que quer pensar a sociedade haitiana coletivamente, de modo que a reflexão proposta ali no texto não partiria somente de um "eu" individual, mas da representação de um "nós" coletivo.

A evidência decisiva para a construção de tal entendimento é de que o projeto de pesquisa do estudante em questão, ao refletir sobre uma obra literária importante da história do país e ao fazer um paralelo com a realidade vivida no pós-terremoto, tinha como objetivo atualizar o significado do imaginário produzido pela literatura haitiana para os processos políticos de transformação necessários no país. Assim sendo, a escolha entre utilizar o "eu" ou um "nós" (ou ainda uma forma impessoal), mais do que uma opção estilística se configurou como uma opção política, que, desafiando as (atuais) convenções e utilizando um outro formato - marcado por uma modalização do eu na forma do plural de modéstia - redefiniu situadamente a convenção de escrita em voga na atualidade para adequá-la à construção de um lugar de escrita transnacional.

Essa escrita transnacional, em uma outra versão do projeto por nós discutida, veio marcada também pela reflexão de um dos mais importantes autores brasileiros do campo dos estudos literários, "Antônio", que escreveu "O Direito à Literatura". Explico: o uso do primeiro nome na referência a Antônio Cândido, o qual pode causar estranhamento, é devido a um elemento cultural haitiano relacionado ao 
modo de fazer referência aos nome pessoais. A hierarquia presente na cultura brasileira entre nome e sobrenome, no Haiti, não se organiza da mesma forma, podendo haver alternância, daí a confusão entre Antônio e Cândido que ficou registrada no texto e nas referências do trabalho de E3.

\section{CONSIDERAÇÕES FINAIS}

O conjunto de dados apresentado aqui aponta para modos específicos de apropriação dos conhecimentos sobre as práticas de letramento acadêmico e sobre usos específicos da escrita acadêmica que podem representar formas de resistência e desafio às convenções institucionalizadas. Esse processo de construção de um saber reflexivo sobre a escrita acadêmica que parte das trajetórias sociais específicas desses estudantes no país de origem é desdobrado no país de destino e reconfigurado com características próprias. Processo este que está estreitamente correlacionado à apropriação da escrita acadêmica como uma ferramenta política para projetos individuais, que, refletindo as questões nacionais do Haiti, são construídos transnacionalmente.

Essa apropriação da escrita acadêmica entre realidades socioculturais distintas permite a construção de um conhecimento no entrecruzamento de fronteiras. A escrita de E3, nesse sentido, é representativa de um interesse comum dos vários estudantes haitianos que participavam do curso de pensar seu país, sua nação e seus projetos de futuro e transformação da sua realidade social. Outros temas de pesquisa dos estudantes estavam relacionados à história do Haiti, às políticas educacionais locais, entre outras problemáticas, ou, ainda, às suas próprias trajetórias e/ou às de outros haitianos no Brasil. Esse interesse emerge como parte da construção de um discurso que questiona as imagens propagadas sobre o Haiti, a imigração haitiana e os haitianos e o lugar subalterno a eles relegado na sociedade brasileira e na dinâmica do capitalismo global.

Esse duplo movimento - que envolve gestos de apropriação e desafio na escrita acadêmica - aponta para a necessidade de reflexões mais profundas e avançadas sobre o seu significado. Se, por um lado, a apropriação representa uma acomodação de um modo de fazer ciência específico, com a possibilidade de abrir espaços para o uso dos múltiplos recursos linguísticos dos estudantes, por outro, o gesto de desafiar, marcado pelo inconformismo, pode apontar para um questionamento dos modelos epistemológicos dominantes fundados na modernidade, na colonialidade e no imperialismo. Segundo Sito (2018), essas estratégias de apropriação, subversão e reexistência, denominadas pela autora como "escritas afirmativas", subvertem 
a colonialidade do saber (QUIJANO, 2005), ao visibilizar os conhecimentos de grupos historicamente marginalizados. Na linha das reflexões de Santos e Meneses (2010), isso pode contribuir para o reconhecimento de múltiplas experiências de compreensão do mundo e a valorização da diversidade de saberes, fazendo com que "a intencionalidade e a inteligibilidade das práticas sociais seja a mais ampla e democrática" (SANTOS e MENEZES, 2010, p, 26).

É importante reconhecer também as implicações pedagógicas do projeto desenvolvido. Windle (2017), em uma discussão sobre aspectos da produção acadêmica na linguística aplicada brasileira, questiona o modo como essa escrita pode vir marcada por um posicionamento a respeito de processos globais que produz a ilusão de um centro dêitico universal que ignora as especificidades do contexto onde são produzidas. Nesse sentido, uma pedagogia dos letramentos acadêmicos precisa estar comprometida com a busca de um entendimento dos múltiplos lugares de origem de produção de conhecimento, o que inclui uma escuta atenta aos modos de construção de posicionamento dos estudantes de grupos minoritários/ minoritarizados como, por exemplo, em situações transnacionais, entendendo seus modos de compreender o mundo e o perfil de conhecimento que eles querem construir em seus discursos não só localmente, mas também transnacionalmente, fortalecendo suas vozes.

\section{$\overline{\text { REFERÊNCIAS }}$}

ALPHONSE, F.; MACEDO, J. R. (2017). O programa Pró-Haiti nas universidades públicas brasileiras (2011-2016). Temáticas, v. 25, n. 49/50, pp. 233-270

AMADO, R. S. (2011). Português como Segunda Língua para Comunidades de Trabalhadores Transplantados. Revista da SIPLE, v. 2 Disponível em: http://www.siple.org.br/index. php? option $=$ com_content $\&$ view $=$ article $\&$ id $=173: 7$-portugues - como-segundalingua-para-comunidades-de-trabalhadores-transplantados\&catid $=57$ : edicao2\&Itemid=92 Acesso em: 1 nov. 2018.

ARCHANJO, R. (2016) Saberes sem fronteiras: políticas para as migrações pós- modernas. D.E.L.T.A., v. 32, p. 2, p. 515-541

ASSIS-PETERSON, A.A.; COX, M. I. P. (2007). Transculturalidade e Transglossia: para compreender o fenômeno das fricções linguístico-culturais em sociedades contemporâneas sem nostalgia. In: Bortoni-Ricardo, S. M.; Cavalcanti, M. C. (Eds.), Transculturalidade, Linguagem e Educação. Campinas: Mercado de Letras, pp. 23-43. 
BAENINGER, R. A.; PERES, R. G. (2017). Migração de crise: a imigração haitiana para o Brasil. Revista Brasileira de Estudos da População. Belo Horizonte, v. 34, n. 1, pp. 119-143 Disponível em: http://www.scielo.br/scielo.php?script $=$ sci_arttext \&pid= S0102$30982017000100119 \& \operatorname{lng}=$ pt\&nrm=iso. Acesso em: 15 nov. 2018.

BAENINGER, R. (Org.) (2013). Migração Internacional. Campinas, Núcleo de Estudos de População, Nepo-Unicamp.

BERSANI, A. E.; JOSEPH, H. (2017). Dinâmicas migratórias haitianas no Brasil: desafios e contribuições, Temáticas, volume especial, n. 49/50.

BIZON, A. C. C. (2013). Narrando o exame CELPE-BRAS e o convênio PEC-G: a construção de territorialidades em tempos de internacionalização. Tese de Doutorado em Linguística Aplicada. Instituto de Estudos da Linguagem, Unicamp, Campinas.

BIZON, A. C. C.; CAVALCANTI, M. C. (2018). Narrating lived experiences from the margins: the voices of two undergraduate students from the Democratic Republic of Congo at a brazilian university. In: Cavalcanti, M. C.; Maher. T. J. M. (Eds.) Multilingual Brazil: Language Resources, Identities and Ideologies in a Globalized World. New York \& Oxon: Routledge, 2018, pp. 225-240.

BIZON, A. C. C.; DANGIÓ, G. (2018). Vozes do Programa Emergencial Pró-Haiti: Narrativas de racialização do ser haitiano. REVISTA X, v. 1, n. 1, pp. 168-191.

BIZON, A. C. C.; DINIZ, L. (Orgs.) (2018). Dossiê Especial: Português como Língua Adicional em contextos de minorias: (co)construindo sentidos a partir das margens. REVISTA $X$, dossiê, $v .1, n 1$.

BLOMMAERT, J. (2005). Discourse: A critical introduction. Cambridge: Cambridge University Press.

BLOMMAERT, J. (2007). Sociolinguistics and Discourse Analysis: Orders of Indexicality and Polycentricity. Journal of Multicultural Discourses, v. 2, n. 2, pp. 115-130.

BOLSMANN, C.; MILLER, H. (2008). International student recruitment to universities in England: Discourse, rationales and globalisation. Globalisation, Societies and Education, $v$. $6, n .1$, pp. $75-88$.

BRASIL (2010). Ministério das Relações Exteriores. Memorando de entendimento entre o Governo da República Federativa do Brasil e o Governo da República do Haiti para a reconstrução, o fortalecimento e a recomposição do Sistema de Educação Superior do Haiti. Disponível em: <http://www.jusbrasil.com.br/diarios/1590414/pg-126secao-1-diario-oficial-da-uniao-doude- 30-03-2010>. Acesso em: 20 nov. 2018. 
CAPES (2010). Portaria No 092, de 28 de abril de 2010. Institui o Programa Emergencial PRÓHAITI em Educação Superior dispõe sobre os procedimentos para operacionalização das atividades do programa. Disponível em: http://www.capes.gov.br/images/stories/ download/legislacao/Portaria09228abr2010_ProHAITI_AlterPort-171-2012.pdf Acesso em: 20 nov. 2018.

CAPES (2012a). Portaria No 171, de 6 de dezembro de 2012. Altera a Portaria de No 92, de 27 de abril de 2010. Disponível em: < http://www.capes.gov.br/images/stories/download/ legislacao/Portaria171-6dez12_HAITI.pdf>. Acesso em: 14 de nov. de 2018.

CAPES (2012b). Anexo da Portaria N.171, de 6 de dezembro de 2012. Disponível em: http://www. capes.gov.br/images/stories/download/bolsas/Anexol-ProHaiti-12dez12.pdf Acesso em: 14 de nov. de 2018.

CARNEIRO, A.S.R. (2014). Políticas Linguísticas e Identidades Sociais em Trânsito: Língua(gem) e construção da diferença em Timor-Leste. Tese de Doutorado em Linguística Aplicada. Instituto de Estudos da Linguagem, Unicamp, Campinas.

CARNEIRO, A. S. R., D’OLIVO, F. M. (2012). Haitianos no Brasil: ideologias linguísticas em conflito no processo de ensino-aprendizagem do português como segunda língua. Leitura. Teoria \& Prática. v.58, pp.566-575.

CARTER, A.; LILLIS, T.; PARKIN, S. (2009). Why writing matters: Issues of access and identity in writing research and pedagogy. Amsterdam: John Benjamins.

CAVALCANTI, M. C. (2006). Um olhar metateórico e metametodológico em pesquisa em lingüística aplicada: implicações éticas e políticas. In: Moita Lopes, L. P. Por uma Linguística Aplicada Indisciplinar. São Paulo: Parábola, pp. 233-252.

CAVALCANTI, M. C. (2011). Multilinguismo, transculturalismo e o (re)conhecimento de contextos minoritários, minoritarizados e invisibilizados. In: Magalhães, M.C.C.; Fidalgo, S.S. (Orgs.) Questões de Método e de Linguagem na Formação Docente. Campinas: Mercado de Letras, pp. 171-185.

CAVALCANTI, M. C.; BORTONI-RICARDO, S. M. (Orgs.) (2007). Transculturalidade, Linguagem e Educação. Campinas: Mercado das Letras.

CAVALCANTI, M. C.; MAHER. T. J. M. (Eds.) (2018). Multilingual Brazil: Language Resources, Identities and Ideologies in a Globalized World. New York \& Oxon: Routledge, 2018.

COUPLAND, N. (2007). Style: Language variation and identity. New York \& Cambridge: Cambridge University Press. 
COX, M. I. P.; ASSIS-PETERSON, A. A. (Orgs.) (2001) Cenas de Sala de Aula. Campinas: Mercado de Letras.

DEVITT, A. Teaching critical genre awareness. (2009). In: Bazerman, C. Bonini, A.; Figueiredo, D. (Eds.) Genres in a Changing World. Fort Collins, Colorado: The Wac Clearing House; West Lafayette, Colorado: Parlor Press, pp. 337-351.

DU BOIS, J. (2007). The Stance Triangle. In: Englebretson, R. Stancetaking in discourse. Amsterdam: John Benjamins, pp. 139-182.

FERRAZ, A.; PINHEIRO, I. M. (2014). O desafio pós Celpe-Bras: relações entre o exame e o Programa de Estudantes- Convênio de Graduação. In: Dell'Isola, R. L. P. O exame de proficiência Celpe-Bras em foco. Campinas: Pontes, pp. 131-141.

FIAD, R. S. Reescrita, Dialogismo e Etnografia. (2013). Linguagem em (Dis)curso, v. 13, n. 3, pp. 463-480

FIAD, R. (2015). Algumas considerações sobre os letramentos acadêmicos no contexto brasileiro. Pensares em Revista, n. 6, pp. 23-34.

FISCHER, A. (2015). "Hidden Features" and "Overt Instruction" in Academic Literacy Practices: A Case Study in Engineering. In: Lillis, T.; Harrington, K.; Lea, M. R.; Mitchell, S. Working with academic literacies: case studies towards transformative practice. Anderson, South Carolina : Parlor Press ; Fort Collins, Colorado: WAC Clearinghouse, 2015, pp. 75-85.

FRANCO, R. A. S. R.; CASTANHEIRA, M. L. (2016). Práticas de Letramento Acadêmico no Facebook. Ilba do Desterro v. 69, n. 3, pp. 13-28.

HAITI (2010). Plan d'action pour le relèvement et le développement national d'Haïti, les grands chantiers pour l'avenir. Disponível em: whc. unesco.org/document/106590. Acesso em: 20 nov. 2018.

HAMANN, E. P; TEIXEIRA, C. A. R. (Orgs.) (2017). A participação do Brasil na MINUSTAH (2004-2017): percepções, lições e práticas relevantes para futuras missões. Instituto Igarapé e CCOPAB. Disponível em: https://igarape.org.br/wp-content/uploads/2017/10/1610-2017-web-AE-MINUSTAH-2017.pdf Acesso em: 20 nov. 2018.

HARRÉ, R.; VAN LANGENHOVE, L. (1991). Varieties of positioning. Journal for the Theory of Social Bebaviour, v. 21, n. 4, 1991, pp. 393-407.

HARRÉ, R.; VAN LANGENHOVE, L. (Eds.) (1999). Positioning theory: Moral contexts of intentional action. Oxford: Blackwell, 1999. 
HYMES, D. H. (1972). Models of the interaction of language and social life. In: Gumperz, J. J. and Hymes, D. H. (Eds.) Directions in sociolinguistics: The ethnograpby of communication. New York: Holt, Rinehart \& Winston, pp. 35-71.

JAFFE, A. (2009) Introduction: The Sociolinguistics of Stance. In: Jaffe, A. (Ed.). Stance: Sociolinguistic Perspectives. Oxford: Oxford University Press, pp. 1-28

KNIGHT, J. (2004). Internationalization remodeled: definition, approaches and rationales. Journal of Studies in International Education, v. 8, n. 1, pp. 5-31.

LEA, M.R.; STREET, B. (1998). Student writing in higher education: an academic literacies approach. Studies in Higher Education, v. 23, n. 2, pp. 157-173.

LILLIS, T. (1999). Whose "Common Sense"? Essayist literacy and the institutional practice of mystery. In: Jones, C.; Turner, J.; Street, B. (Orgs.). Students writing in the university: cultural and epistemological issues. Amsterdam: John Benjamins, pp. 127-148.

LILLIS, T. (2003). An 'academic literacies' approach to student writing in higher education: drawing on Bakhtin to move from 'critique' to 'design'. Language and Education, v. 17, n. 3, pp. 192-207.

LILLIS, T.; SCOTT, M. (2007). Defining academic literacies research: issues of epistemology, ideology and strategy. Journal of Applied Linguistics (JAL), Londres, v. 4, n.1, pp. 5-32.

LILLIS, T.; HARRINGTON, K.; LEA, M. R.; MITCHELL, S. (2015) Introduction. In: Lillis, T.; Harrington, K.; Lea, M. R.; Mitchell, S. Working with academic literacies: case studies towards transformative practice. Anderson, South Carolina : Parlor Press; Fort Collins, Colorado: WAC Clearinghouse, pp. 3-22.

MACHADO, A. R.; LOUSADA, E. G.; ABREU-TARDELLI, L.S. (2004a) Resumo. São Paulo: Parábola.

MACHADO, A. R..; LOUSADA, E. G.; ABREU-TARDELLI, L.S. (2004b) Resenba. São Paulo: Parábola.

MACHADO, A. R. LOUSADA, E. G.; ABREU-TARDELLI, L.S. (2005) Planejar gêneros acadêmicos. São Paulo: Parábola.

MAHER, T. M. (2007a) Do casulo ao movimento: a suspensão das certezas na educação bilíngue e intercultural. In: Cavalcanti, M.; Bortoni-Ricardo, S. M. (orgs.) Transculturalidade, linguagem e educação. Campinas: Mercado de Letras, pp. 67-94. 
MAHER, T. M. (2007b). A educação do entorno para a interculturalidade e o plurilinguismo. In: Kleiman, A. B.; Cavalcanti, M. C. (Orgs.) Linguística Aplicada: suas faces e interfaces. Campinas: Mercado de Letras, pp. 255-270.

MASSEY, D.; ARANGO, J.; HUGO; G. KOUAOUCI, A.; PELLEGRINO, A. TAYLOR, A. E. (1999) Worlds in Motion: Understanding International Migration at the End of the Millennium, Oxford: Oxford University Press.

MIRANDA, Y. C. C. (2016). Projeto "Pelo Mundo": a configuração de uma política linguística em um curso de português como língua adicional para candidatos ao Programa de Estudantes-Convênio de Graduação (PEC-G). Dissertação de Mestrado em Linguística Aplicada. Faculdade de Letras, Universidade Federal de Minas Gerais.

MOITA LOPES, L. P. (2006). Uma linguística aplicada mestiça e ideológica: interrogando o campo como linguista aplicado. In: Moita Lopes, L. P. (Org.) Por uma Linguística Aplicada Indisciplinar. São Paulo: Parábola, pp. 13-44.

MOITA LOPES, L. P. (org.) (2013). O Português no Século XXI. Cenário geopolítico e sociolinguístico. São Paulo: Parábola.

PAIVA, O. C.; MOURA, S. (2008). Hospedaria de Imigrantes de São Paulo. São Paulo: Paz e Terra.

PASQUOTTE-VIEIRA, E.; FIAD, R. S. (2015). Letramentos acadêmicos: entre práticas letradas acadêmicas e não acadêmicas. Linguagem \& Ensino, Pelotas, v.18, n.1, pp. 125-150.

PINTO, J. P. (2014). Hegemonias, contradições e desafios em discursos sobre língua no Brasil. In: Correa, D. A. (Org.) Política Linguística e ensino de línguas. Campinas: Pontes, pp. $59-72$.

QUIJANO, A. (2005). Colonialidade do poder, eurocentrismo e América Latina. In: Lander, E. (Org). A colonialidade do saber: eurocentrismo e ciências sociais. Buenos Aires: CLACSO, pp. 227-278.

REIZ, N.; O'LEAR, S. (2016). Spaces of violence and (in)justice in Haiti: a critical legal geography perspective on rape, UN peacekeeping, and the United Nations status of forces agreement, Territory, Politics, Governance, v. 4., n. 4, pp. 453-471.

SAINTIL, S. A. R. (2018). Breve memória de um aprendiza: um olhar sobre meus caminhos em direção à língua portuguesa. REVISTA X, v. 13, n. 1, pp. 161-167.

SANTOS, B. S.; MENESES, M. P. (2010). Introdução. In: Santos, B. S.; Meneses, M. P. (Orgs.) Epistemologias do Sul. São Paulo: Cortez, pp. 15-27. 
SASSEN, S. (1990). The Mobility of Labor and Capital: A Study in International Investment and Labor Flow. New York \& Cambridge: Cambridge University Press.

SEGUY, F. (2014). A catástrofe de janeiro de 2010, a "Internacional Comunitária" e a recolonização do Haiti. Tese de Doutorado em Sociologia. Instituto de Filosofia e Ciências Humanas, Unicamp, Campinas.

SEGUY, F. (2015). Racismo e Desumanização no Haiti. Revista de Educação: Educere et Educare, v.10, n. 20, 2015.

SIGNORINI, I. (2002). Por uma teoria da desregulamentação linguística. In: Bagno, M. (Org.) Linguística da norma. São Paulo: Ediçoes Loyola, pp. 93-125.

SIGNORINI, I. (2006). A questão da língua legítima na sociedade democrática: um desafio para a linguística aplicada contemporânea. In: Moita Lopes, L. P. Por uma Linguística Aplicada Indisciplinar. São Paulo: Parábola, pp. 169-189.

SIGNORINI, I. (2008). Metapragmáticas da língua em uso: unidades e níveis de análise. In: Signorini, I. Situar a língua[gem]. São Paulo: Parábola, pp. 117-148.

SIGNORINI, I. (2009). Complexidade Linguística e Ensino de Língua Portuguesa. In: Marçalo, M. J.; Lima-Hernandes, M. C.; Esteves, E.; Fonseca, M. C.; Gonçalves, A. L.; Vilela, A. L.; Silva, A. A. (Eds.) Anais do II SIMELP, Língua Portuguesa: ultrapassar fronteiras, juntar culturas, Évora: Universidade de Évora. Disponível em: http://www.simelp2009.uevora.pt/pdf/slg14/06.pdf Acesso em: 8 out. 2014.

SILVA, K. C. e SIMIÃO, D. S. (Orgs.) (2007). Timor-Lestepor trás dopalco: Cooperação internacional e dialética da formação do Estado. Belo Horizonte: Editora UFMG.

SILVA, K. C. (2012). Global flows of government practices: development technologies and their effects. Vibrant (Florianópolis), v. 9, pp. 70-102

SILVERSTEIN, M. (1993). Metapragmatic discourse and metapragmatic function. In: Lucy, J. (Ed.) Reflexive language. Cambridge \& New York: Cambridge University Press, pp. 33-58.

SITO, L. R. S. (2018). Ensaiando estratégias das artes letradas nas zonas de contato: trajetórias de letramento acadêmico, ações afirmativas e políticas de conhecimento. Rev. Bras. Linguíst. Apl., Abead of Print.

STEIN, S. (2017). Internationalization for an uncertain future: tensions, paradoxes, and possibilities. The Review of Higher Education, v. 41, n. 1, pp. 3-32. 
THOMAZ, O. R. (2010). O terremoto no Haiti, o mundo dos brancos e lougawou. Novos Estudos, 86, pp. 23-39.

THOMAZ, O. R. (2011). Eles são assim: racismo e o terremoto de 12 de janeiro de 2010 no Haiti. Cadernos de Campo, São Paulo, n. 20, pp. 273-284.

THOMAZ, O. R.; NASCIMENTO, S. (2010). Da crise às ruínas: impacto do terremoto sobre o ensino superior no Haiti. Ministério da Educação. Coordenação de Aperfeiçoamento de Pessoal de Ensino Superior.Programa Pró Haiti. Disponível em: http://www2.prpg. unicamp.br/noticias/dacriseasruinas.pdf Acesso em: 20 de nov. de 2018.

VERTOVEC, S. (1999). Conceiving and researching transnationalism. Etbnic and Racial Studies, v. 22, n. 2, pp. 447-462

WALLERSTEIN, I. (1974). The Rise and Future Demise of the World Capitalist System: Concepts for ComparativeAnalysis. Comparative Studies in Society and History, v. 16, n. 4, pp. 387-415

WINDLE, J. (2017). Hidden features in global knowledge production: (re)positioning theory and practice in academic writing. Rev. bras. linguist. apl. [online], vol.17, n.2, pp. 355-378.

WOOLARD, K. A.; SCHIEFFELIN, B. B. (1994). Language Ideology, Annual Review of Antbropology. 23, pp. 55-82.

WORTHAM, S. (2001). Narratives in action: a strategy for research and analysis. New York: Teachers College Press.

Recebido: 3/12/2018

Aceito: 21/02/2019

Publicado: 29/03/2019 